\title{
Exhaled Breath Temperature in Asthmatics and Controls after Eucapnic Voluntary Hyperventilation and a Methacholine Challenge Test
}

\author{
Henning Svensson Leif Bjermer Ellen Tufvesson \\ Respiratory Medicine and Allergology, Department of Clinical Sciences, Lund University, Lund, Sweden
}

\section{Key Words}

Asthma - Eucapnic voluntary hyperventilation .

Methacholine Exhaled breath temperature

\begin{abstract}
Background: It has been suggested that exhaled breath temperature (EBT) is increased in asthmatic subjects. Objectives: Our aim was to investigate EBT in asthmatics compared to healthy controls before and after eucapnic voluntary hyperventilation $(\mathrm{EVH})$ and a methacholine challenge test (MCT). Methods: A total of 26 asthmatics and 29 healthy controls were included. Forced expiratory volume in $1 \mathrm{~s}$ $\left(\mathrm{FEV}_{1}\right), \mathrm{EBT}$ and oral, axillary and auricular temperatures were measured before and after EVH and MCT. Results: $\mathrm{FEV}_{1} \%$ predicted (\%p) was significantly lower in asthmatic subjects compared to healthy controls at all time points. EBT was significantly increased in all subjects 15-30 min after EVH and 5-45 min after MCT. Oral temperature displayed a similar pattern of increase, in contrast to axillary and auricular temperature, and correlated with EBT before and after both of the challenge tests. EBT after 5 min correlated with the largest drop in $\mathrm{FEV}_{1} \% \mathrm{p}$ after $\mathrm{EVH}$ in asthmatic subjects. No significant differences or changes in EBT were found when comparing asthmatics to healthy controls before or after any of the tests. Conclusions: EBT is increased after both EVH and $M C T$, possibly reflecting a vascular response. This is related to both the fall in $\mathrm{FEV}_{1}$ and to oral temperature, suggesting an effect on the whole respiratory tract including the oral
\end{abstract}

www.karger.com/res

\section{KARGER}

E-Mail karger@karger.com cavity. No differences in EBT are seen between asthmatics and healthy controls, indicating that the increase in EBT is mainly physiological rather than pathophysiological.

(c) 2013 S. Karger AG, Basel

\section{Introduction}

Asthma is characterized by inflammation of the airways, with inflammatory cells present as well as airway remodeling, increased vascularization and bronchial hyperresponsiveness (BHR). Provocation testing for detecting BHR in asthmatics has gained importance for diagnosis and for monitoring disease activity, guiding the dosing of inhaled steroids [1].

Exhaled breath temperature (EBT) is a potential biomarker for airway inflammation. It has been shown to relate to disease exacerbations [2-4] as well as to vascular [5] and fibrous remodeling [6] of the airways, and to correlate with levels of exhaled nitric oxide (NO) in childhood and adult asthma $[7,8]$. Sub-epithelial blood vessel density is higher in asthmatic subjects than in healthy controls [9], and the hypothesis is that increased blood flow during airway inflammation would result in heating of the ventilated air to a higher temperature [5]. Some studies have shown that EBT is elevated in asthmatics compared to healthy controls $[2,8,10]$, but research on the relationship between EBT and BHR is limited. In a previous study, we found that an increase in EBT corre- (c) 2013 S. Karger AG Base

0025-7931/13/0872-0149\$38.00/0 
lated with a decrease in forced expiratory volume in $1 \mathrm{~s}$ $\left(\mathrm{FEV}_{1}\right)$ in both asthmatics and controls after an exercise challenge test [11]. A similar correlation has been found in asthmatic children [12]. In addition, we found that there was a prolonged increase in EBT after exercise in asthmatics for whom the $\mathrm{FEV}_{1}$ fell during the test compared to asthmatic subjects for whom it did not fall. This indicates a link between EBT and airway inflammation, but the potential of a clinical implication of EBT is yet to be determined. Increased baseline levels of 8 -isoprostane, a marker of oxidative stress, have been found in exhaled breath condensate of asthmatic children with BHR after an exercise challenge test, supporting the notion that persistent airway inflammation is important for exercise-induced bronchoconstriction to occur [13].

Eucapnic voluntary hyperventilation $(\mathrm{EVH})$ is an indirect challenge test, similar to the exercise challenge test, where the inflammatory cells of the airways are triggered to release mediators $[14,15]$, causing smooth muscle cell constriction and vasodilatation. The triggering factor for this release is believed to be an increased osmolarity of the periciliary fluid covering the respiratory mucosal membrane [16], due to increased loss of water to the air when there is a high rate of ventilation. The specificity of an indirect challenge test is considered high, as, in theory, inflammation is required for a positive result to occur.

Methacholine is believed to act directly on the muscarinic receptors [17] of smooth muscle cells, endothelial cells and mucus-producing cells, inducing bronchial obstruction, vasodilatation and mucus production. The sensitivity of a methacholine challenge test (MCT) is high, while a positive test has a low diagnostic specificity. The presence of inflammation and chronic remodeling of the airways are both believed to increase reactivity to methacholine [18].

The aim of this study was to investigate changes in EBT after EVH and MCT, and to compare it to changes in body temperature. EVH is believed to trigger bronchoconstriction and vasodilatation through the release of inflammatory mediators, similar to an exercise challenge test. Methacholine was used as an additional challenge, reflecting another pathophysiological mechanism. We hypothesized that those subjects who responded to EVH with bronchoconstriction would increase their EBT to a greater extent than those who did not, due to the probable vasodilatation following the release of mediators from airway inflammatory cells. An increase in EBT would also theoretically be seen after MCT, where the pharmacological effect of methacholine acts not only on smooth muscle cells but also induces vasodilatation. A secondary aim
Table 1. Subject characteristics

\begin{tabular}{|c|c|c|}
\hline & $\begin{array}{l}\text { Controls } \\
(\mathrm{n}=29)\end{array}$ & $\begin{array}{l}\text { Asthmatics } \\
(\mathrm{n}=26)\end{array}$ \\
\hline Males/females, $\mathrm{n}$ & $16 / 13$ & $16 / 10$ \\
\hline Age, years & $25(23-26)$ & $24(22-27)$ \\
\hline Baseline $\mathrm{FEV}_{1} \% \mathrm{p}$ & $104(97-107)$ & $95(90-98)$ \\
\hline $\mathrm{FEV}_{1}$ drop $\geq 10 \%$ after EVH, $\mathrm{n}$ & 6 & 14 \\
\hline $\begin{array}{l}\text { Fall in } \mathrm{FEV}_{1} \% \mathrm{p} \text { after } \mathrm{EVH} \text {, } \\
\text { percentage units }\end{array}$ & $6(4-9)$ & $10(6-15)$ \\
\hline $\mathrm{FEV}_{1}$ drop $\geq 20 \%$ after MCT, $\mathrm{n}$ & 7 & 16 \\
\hline $\begin{array}{l}\text { Fall in } \mathrm{FEV}_{1} \% \mathrm{p} \text { after } \mathrm{MCT}, \\
\text { percentage units }\end{array}$ & $10(7-20)$ & $21(13-28)$ \\
\hline Atopy, n & 7 & 20 \\
\hline $\begin{array}{l}\text { ICS }(400-800 \mu \mathrm{g} \\
\quad \text { budesonide/day), } \mathrm{n}\end{array}$ & 0 & 20 \\
\hline Exhaled NO, ppb & $14.7(9.9-23.5)$ & $17.1(14.9-26.4)$ \\
\hline
\end{tabular}

Data are expressed as a median (interquartile range), where appropriate. For baseline $\mathrm{FEV}_{1} \% \mathrm{p}$ and exhaled NO values, a mean of the two registrations before each test is used for each subject.

was to investigate whether an increase in airway resistance would affect the change in EBT, due to narrowing of the airways.

\section{Materials and Methods}

\section{Subjects}

Twenty-six subjects with a doctor's diagnosis of asthma according to the guidelines of the Global Initiative for Asthma [19] were investigated (table 1). Twenty-nine healthy subjects with no diagnosis of asthma or any respiratory symptoms were used as controls. All subjects were interviewed concerning their previous and present health, and asthmatic subjects filled out an Asthma Control Test questionnaire. Subjects with respiratory tract infections (within the last 3 weeks) or any other medical conditions (apart from asthma) affecting their health were excluded, as were subjects with a history of smoking. The subjects were not allowed to drink coffee for at least $6 \mathrm{~h}$ prior to either challenge test or to conduct any form of exercise on the same day. All asthmatic subjects refrained from using shortacting $\beta 2$-agonists for at least $8 \mathrm{~h}$ and long-acting $\beta 2$-agonists and inhaled corticosteroids (ICS) for at least $24 \mathrm{~h}$ prior to any part of the study. All subjects gave written informed consent and the study was approved by the regional Ethics Review Board, Lund.

\section{Study Design}

We conducted tests from the 14 July 2011 to the 1 August 2012. Two different respiratory tract provocation tests, EVH and MCT, were performed in random order by all subjects. At least $48 \mathrm{~h}$ passed between tests. Prior to each test, and after at least 5 min of rest, exhaled NO, spirometry, EBT and axillary, auricular and oral temperatures were measured (in the given order). Thereafter, the subjects performed a provocation test. Afterwards, measurements of spirometry, EBT, axillary, auricular and oral temperatures were 
performed repeatedly during a period of rest, as described below. After completing the measurements, 60 min after the provocation test, $400 \mu \mathrm{g}$ of salbutamol was inhaled by the subject. After another 15 min of rest, a final set of measurements (spirometry, EBT and body temperatures) was conducted.

\section{Eucapnic Voluntary Hyperventilation}

The subjects hyperventilated for 6 min through a mouthpiece connected to a container administering dry hypercapnic air (5\% $\mathrm{CO}_{2}$ ) via a dry air ventilation device (Aiolos Medical AB, Karlstad, Sweden). The air was at an ambient temperature. A nose clip was used, and the flow was set to $26 \times \mathrm{FEV}_{1}$ (baseline value) $1 / \mathrm{min}$. The subjects were supervised at all times and guided by a reservoir balloon attached to the ventilation device, ensuring that the rate and depth of breathing were adequate. The test was considered positive if $\mathrm{FEV}_{1}$ dropped by $\geq 10 \%$ (compared to the baseline value) at any measurement within $30 \mathrm{~min}$ of the end of the hyperventilation.

\section{Methacholine Challenge Test}

For the MCT, a tidal-volume-triggered device (Aerosol Provocation System, APS; Erich Jaeger GmbH) was used. One inhalation of $9 \mathrm{mg} / \mathrm{ml} \mathrm{NaCl}$ was performed first as a negative control. Methacholine was then inhaled repeatedly, with a spirometry performed 2 min after each inhalation and the next inhalation following directly thereafter. Five inhalations were administered with increasing doses $(50,150,300,600$ and $900 \mu \mathrm{g})$, resulting in a maximal cumulative dose of $2,000 \mu \mathrm{g}$ of methacholine. A positive test was defined as a drop of $\mathrm{FEV}_{1}$ by $\geq 20 \%$ to baseline value, in which case the challenge test was considered completed and measurements were made as described below.

\section{Exhaled NO Measurement}

Exhaled NO was measured prior to each of the tests using a NIOX Flex (Aerocrine AB, Stockholm, Sweden) according to recommendations of the American Thoracic Society and European Respiratory Society [20] with an exhalation flow rate of $50 \mathrm{ml} / \mathrm{s}$.

\section{Lung Function Test}

Flow volume spirometry (Jaeger MasterScope, Würzburg, Germany) measuring $\mathrm{FEV}_{1}$ was performed before and 5, 10, 15, 20, 30,45 and $60 \mathrm{~min}$ after the end of each of the provocation tests, and 15 min after inhaling salbutamol. $\mathrm{FEV}_{1} \%$ predicted $(\% \mathrm{p})$ was calculated according to the reference spirometric values of Crapo et al. [21].

\section{EBT Measurement}

EBT was measured using an X-Halo (Delmedica Investments, Singapore) once before and 5, 15, 30, 45 and $60 \mathrm{~min}$ after each of the tests, as well as $15 \mathrm{~min}$ after inhaling salbutamol. Subjects were instructed to breathe tidally, inhaling through the nose and exhaling through the mouth into the device. Measurements took 2-6 min to complete.

\section{Body Temperature Measurements}

Body temperatures were measured before and 5, 15, 30, 45 and $60 \mathrm{~min}$ after each of the provocation tests as well as 15 min after inhaling salbutamol. Oral and axillary temperatures were measured with digital clinical thermometers C402 and C202, respectively (Terumo, Leuven, Belgium). Auricular temperature was measured using a ThermoScan type 6013 (Braun, Kronberg, Germany).

\section{Impulse Oscillometry System}

A Jaeger MasterScreen impulse oscillometry system (IOS; Erich Jaeger $\mathrm{GmbH}$ ) was used to test a subgroup consisting of 22 of the subjects ( 9 asthmatics and 13 healthy controls). IOS was performed before MCT and after each inhalation during the challenge prior to spirometry, as previously described [22]. Subjects used a nose clip and were instructed to press the palms of their hands against their cheeks in order to decrease the influence of movements of the upper airways on IOS parameters. Oscillometric pressure impulses with a pulse sequence of 5 per second and a frequency spectrum between 5 and $35 \mathrm{~Hz}$ were superimposed on tidal breathing for at least $30 \mathrm{~s}$. Airway resistance at $5 \mathrm{~Hz}$ (R5) and $20 \mathrm{~Hz}$ (R20), reactance at $5 \mathrm{~Hz}(\mathrm{X} 5)$, resonant frequency (Fres) and area of reactance integrated from $5 \mathrm{~Hz}$ to Fres (AX) were determined, and R5-R20 was calculated.

\section{Statistical Analyses}

GraphPad Prism version 4.0 was used for statistical analysis. The results are expressed as median (interquartile range) where appropriate. Correlations were calculated using Spearman's correlation test. Comparisons between groups were made by using the Mann-Whitney test. Analysis of paired measurements was made by using Wilcoxon's test. A p value of $<0.05$ (two-tailed) was considered significant. Power calculation was performed based on 2 independent groups of 26 evaluable subjects. With an expected standard deviation of 0.5 , it was possible to detect a significant difference with a power of $94 \%$.

\section{Results}

\section{Subjects}

Twenty subjects (14 asthmatics and 6 controls) had a positive EVH test and 23 (16 asthmatics and 7 controls) had a positive MCT (table 1). Seventeen of the subjects (12 asthmatics and 5 controls) were positive for both challenge tests. There were no significant differences in EBT or $\triangle E B T$ (defined as the difference between baseline EBT and the highest EBT after the challenge test) when comparing those who were positive for both challenge tests to those who were positive for one test only or negative for both tests. The Asthma Control Test score among asthmatic subjects was 21.5 (20-23), and it did not differ between subjects who had a positive EVH or MCT and those who did not.

\section{Lung Function}

As expected, levels of $\mathrm{FEV}_{1} \% \mathrm{p}$ were significantly lower in asthmatic subjects than controls at baseline $(\mathrm{p}=0.002-$ $0.006)$ and 5-60 ( $\mathrm{p}=0.001-0.006) \mathrm{min}$ after both tests, and also after inhaling salbutamol ( $\mathrm{p}=0.003-0.007)$.

All subjects (both asthmatics and controls) experienced a drop in the level of $\mathrm{FEV}_{1}$ after both EVH and MCT $(\mathrm{p}<0.001)$, and $\mathrm{FEV}_{1}$ increased postsalbutamol 


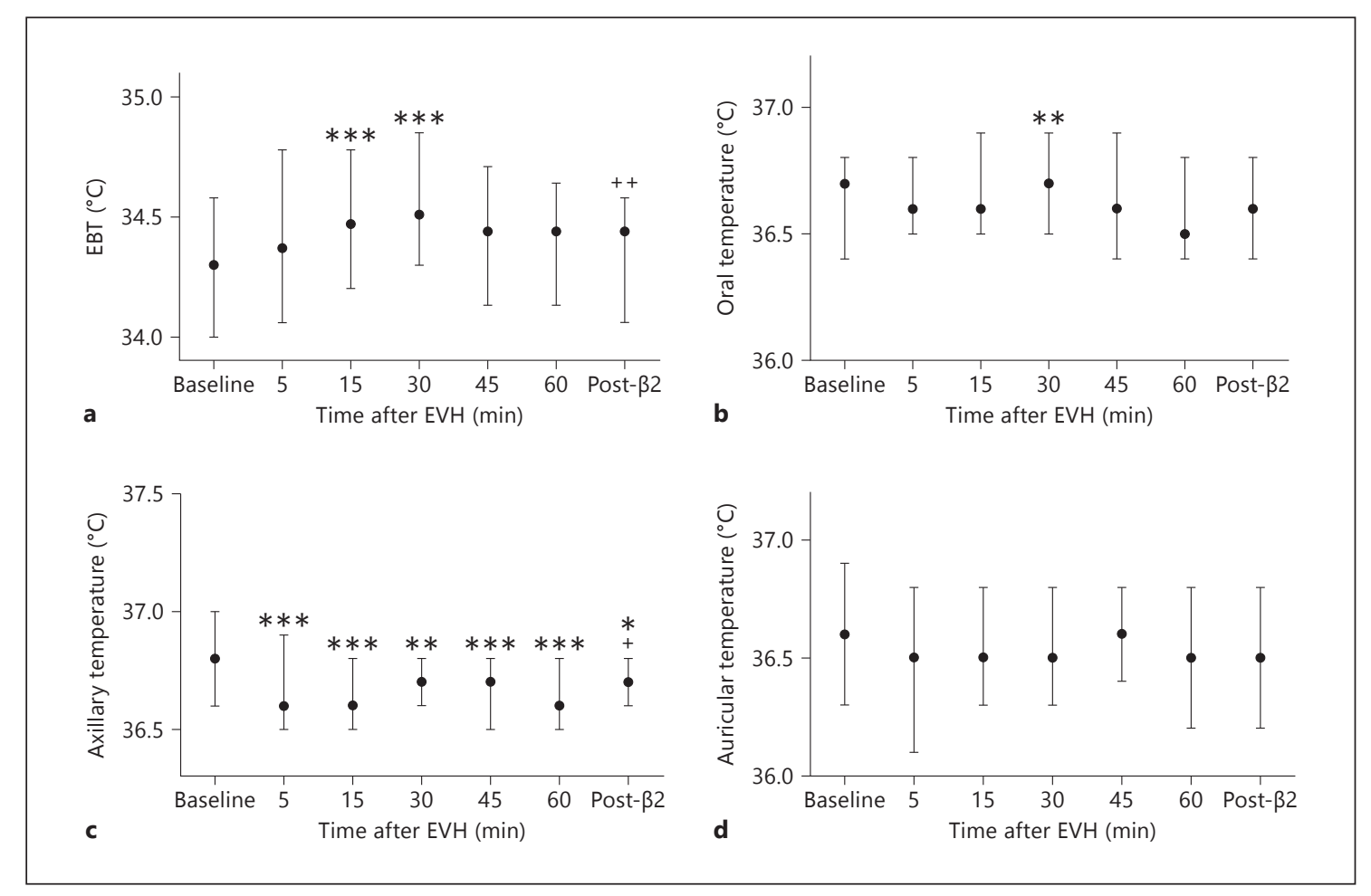

Fig. 1. EBT (a), oral temperature (b), axillary temperature (c) and auricular temperature (d) before (baseline) and 5, 15, 30, 45 and 60 min after EVH and postsalbutamol (Post- $\beta 2)$ in all subjects. ${ }^{*} \mathrm{p}<0.05,{ }^{* *} \mathrm{p}<0.01,{ }^{* * *} \mathrm{p}<$ 0.001: significant difference compared to baseline. ${ }^{+} \mathrm{p}<0.05,{ }^{++} \mathrm{p}<0.01$ : significant difference between measurement after $60 \mathrm{~min}$ and postsalbutamol.

compared to at both baseline $(\mathrm{p}<0.001$ after EVH; $\mathrm{p}=$ 0.040 after MCT) and 60 min after the challenge tests $(\mathrm{p}<$ 0.001 ). A majority of the subjects had their greatest drop in $\mathrm{FEV}_{1}$ at 5-10 min after both EVH $(\mathrm{n}=34)$ and MCT $(\mathrm{n}=42) . \mathrm{FEV}_{1} \% \mathrm{p}$ in all subjects was lowest $5 \mathrm{~min}$ after EVH [90.5\% (83.4-100.2)] and 5 min after MCT [83.4\% (74.7-100.4)].

During EVH, $\mathrm{FEV}_{1} \% \mathrm{p}$ was significantly lower at all time points (except for $45 \mathrm{~min}$ ) in asthmatic subjects with ICS treatment than in those not treated with ICS. Following $\mathrm{MCT}, \mathrm{FEV}_{1} \% \mathrm{p}$ was lower in asthmatic subjects treated with ICS after $15 \mathrm{~min}$ and postsalbutamol, but not at any other time point. There was no difference in $\mathrm{FEV}_{1} \% \mathrm{p}$ between male and female subjects.

\section{Exhaled-Breath Temperature}

EBT was significantly increased compared to baseline following EVH in all subjects after $15 \mathrm{~min}$, and it peaked at $30 \mathrm{~min}$ ( $\mathrm{p}<0.001$; fig. 1a). After MCT, EBT was significantly increased in all subjects compared to baseline at $5-45 \mathrm{~min}$ ( $\mathrm{p}<0.001-0.006$; fig. $2 \mathrm{a})$. EBT peaked $15 \mathrm{~min}$ after MCT.
There were no significant differences between asthmatics and healthy controls in EBT or $\triangle \mathrm{EBT}$ at any time point during the challenge tests (fig. 3) or between subjects with and without a positive challenge test. There were no differences in baseline EBT or $\triangle \mathrm{EBT}$ between asthmatic subjects with and without ICS treatment, between atopic and nonatopic subjects or between male and female subjects.

\section{EBT Correlation with Lung Function}

$\triangle \mathrm{FEV}_{1} \% \mathrm{p}$ (defined as the maximum decrease in $\mathrm{FEV}_{1} \% \mathrm{p}$ : baseline $\mathrm{FEV}_{1} \% \mathrm{p}$ - lowest $\mathrm{FEV}_{1} \% \mathrm{p}$ after the challenge test) after EVH correlated with EBT measured after $5 \mathrm{~min}$ in asthmatic subjects $(\mathrm{p}=0.048, \mathrm{r}=0.392)$, but not in controls $(\mathrm{p}=0.641, \mathrm{r}=-0.091)$, all subjects $(\mathrm{p}=$ $0.421, r=0.111$; fig. $4 a$ ) or when examining into subjects with a positive or negative EVH challenge test (data not shown).

No similar correlation between $\triangle \mathrm{FEV}_{1} \% \mathrm{p}$ and $\mathrm{EBT}$ 5 min was seen after MCT in the asthmatics, the controls or all subjects (fig. $4 \mathrm{~b}$ ).

There was no correlation between $\triangle \mathrm{FEV}_{1} \% \mathrm{p}$ and $\triangle \mathrm{EBT}$ after any of the challenge tests. 


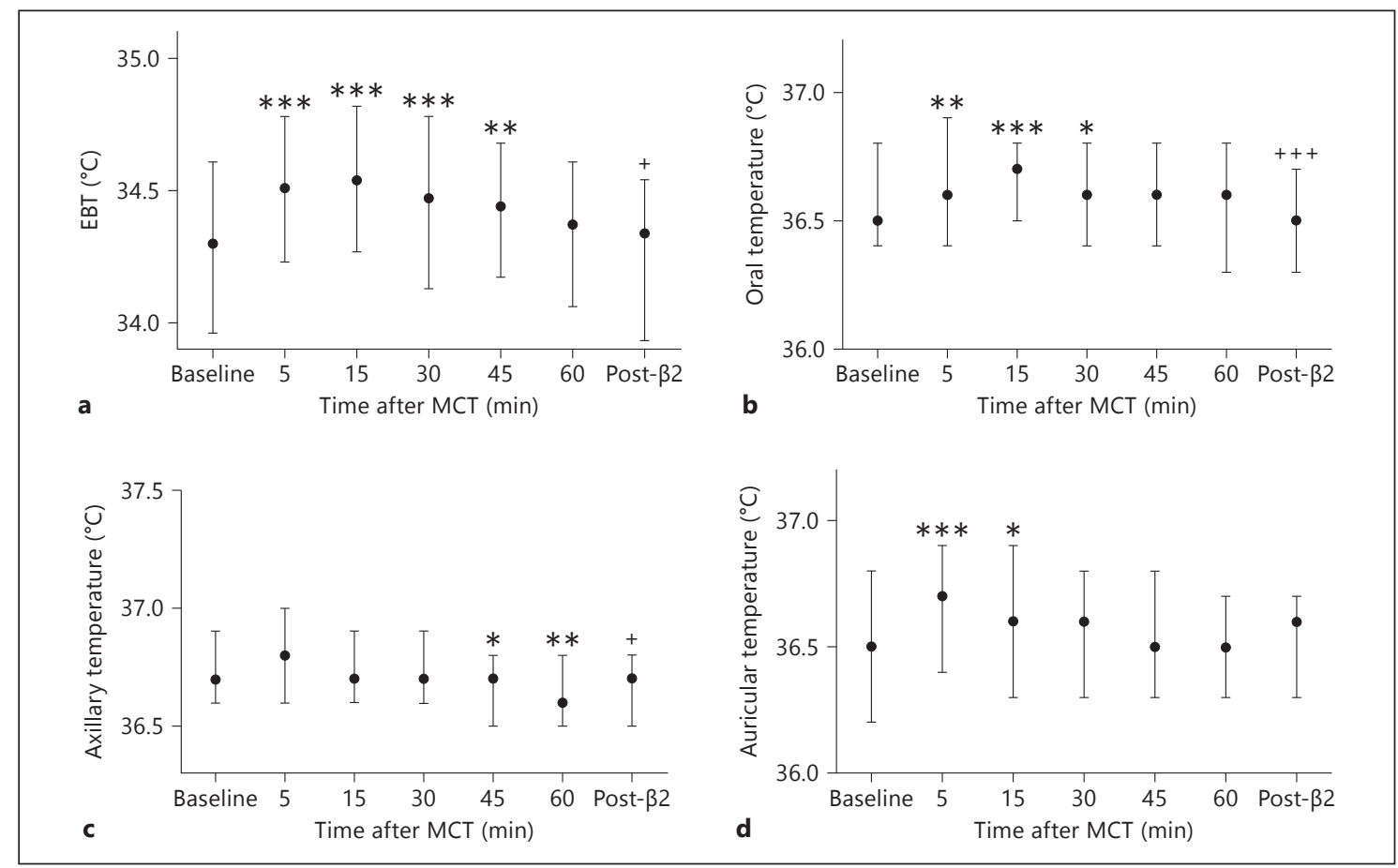

Fig. 2. EBT (a), oral temperature (b), axillary temperature (c) and auricular temperature (d) before baseline and $5,15,30,45$ and 60 min after MCT and postsalbutamol (Post- $\beta 2)$ in all subjects. ${ }^{*} \mathrm{p}<0.05,{ }^{* *} \mathrm{p}<0.01,{ }^{* * *} \mathrm{p}<$ 0.001: significant difference compared to baseline. ${ }^{+} \mathrm{p}<0.05,{ }^{++} \mathrm{p}<0.001$ : significant difference between measurement after $60 \mathrm{~min}$ and postsalbutamol.

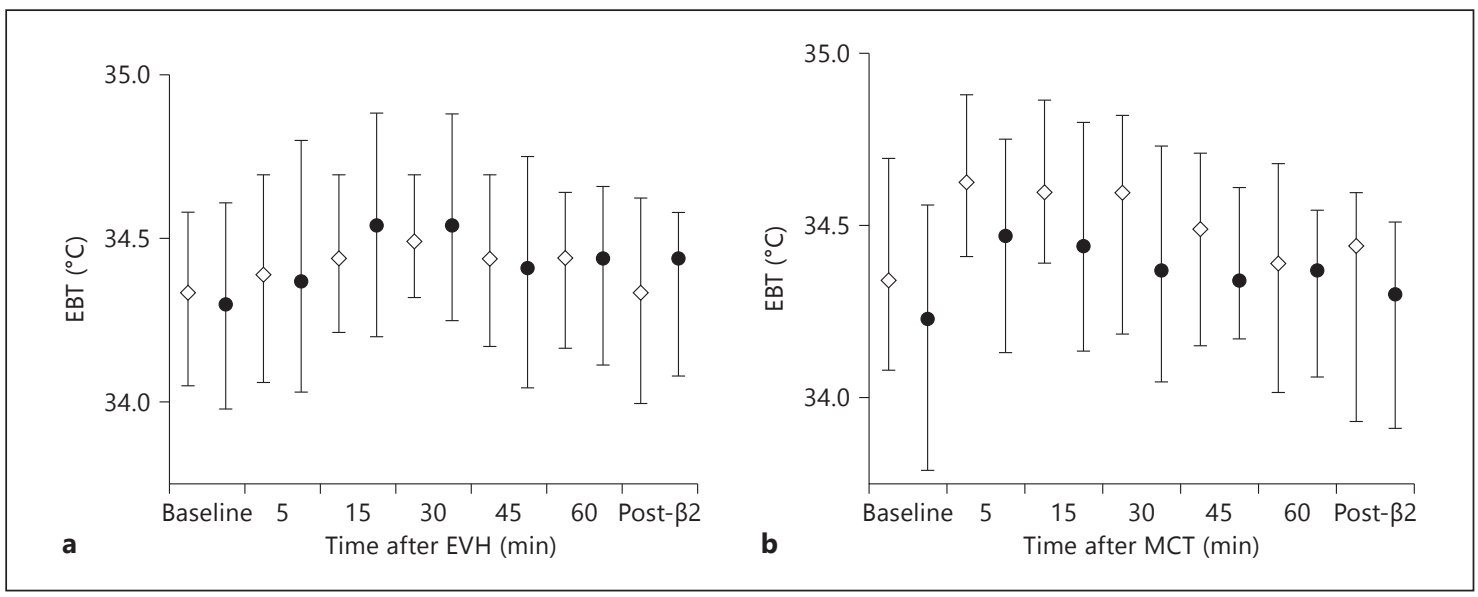

Fig. 3. EBT in asthmatics and controls before baseline and after 5, 15, 30, 45 and 60 min and postsalbutamol (Post- $\beta 2$ ) after EVH (a) and MCT (b). $\diamond=$ Asthmatic subjects; $\bullet=$ healthy controls.

\section{Body Temperatures and Correlations with EBT}

Oral temperature displayed an increase after both EVH and MCT, similar to what was seen in EBT. Oral temperature was significantly elevated in all subjects 30 min after EVH ( $p=0.003$; fig. $1 b)$. After MCT, oral temperature was elevated compared to baseline after 5-30 min ( $<$ 0.001-0.046; fig. 2b).

Neither axillary nor auricular temperatures showed a similar pattern of increase after EVH (fig. 1). On the contrary, axillary temperature was decreased and auricular 


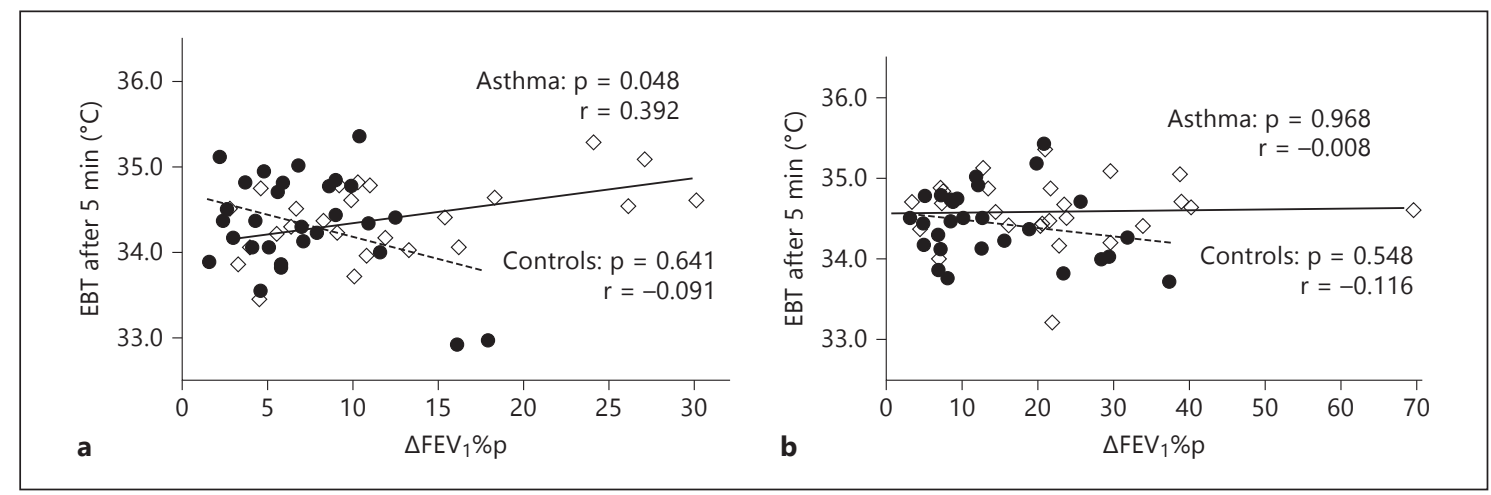

Fig. 4. Correlation between maximum decrease in $\mathrm{FEV}_{1} \% \mathrm{p}\left(\triangle \mathrm{FEV}_{1} \% \mathrm{p}\right.$; defined as baseline $\mathrm{FEV}_{1} \% \mathrm{p}-$ lowest $\mathrm{FEV}_{1} \% \mathrm{p}$ after the challenge test) and EBT at $5 \mathrm{~min}$ after EVH (a) and MCT (b). $\diamond=$ Asthmatic subjects; $\bullet=$ healthy controls; $-=$ correlation in asthmatic subjects; ---- = correlation in controls.

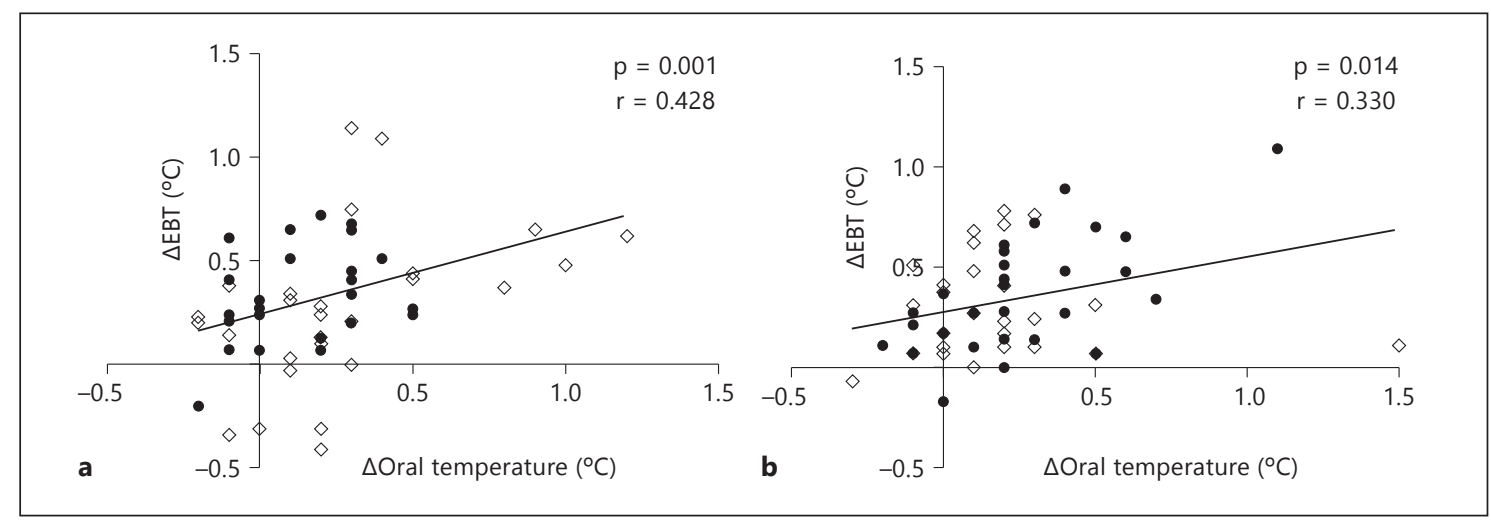

Fig. 5. Correlation between change in $\mathrm{EBT}(\triangle \mathrm{EBT}$; defined as highest EBT after the challenge test - baseline EBT) and change in oral temperature ( $\triangle$ oral temperature; defined as highest oral temperature after the challenge test baseline oral temperature) after $\operatorname{EVH}(\mathbf{a})$ and MCT (b). $\diamond=$ Asthmatic subjects; $\bullet=$ healthy controls; $\frac{-}{=}=$ correlation in all subjects.

temperature was not affected. After MCT, auricular temperature was increased at $5 \mathrm{~min}(\mathrm{p}<0.001)$ and $15 \mathrm{~min}$ $(p=0.013)$ compared to baseline value (fig. $2 d)$, while axillary temperature instead dropped after $45 \mathrm{~min}$ ( $\mathrm{p}=$ 0.020 ) and $60 \mathrm{~min}$ ( $\mathrm{p}=0.009$; fig. $2 \mathrm{c}$ ).

EBT correlated with oral temperature at baseline $(\mathrm{p}=$ $0.044, \mathrm{r}=0.270)$, before EVH and $5 \min (\mathrm{p}=0.032, \mathrm{r}=$ $0.288), 45 \min (\mathrm{p}=0.005, \mathrm{r}=0.372)$ and $60 \min (\mathrm{p}=$ $0.029, \mathrm{r}=0.292)$ afterwards as well as postsalbutamol $(\mathrm{p}<$ $0.001, r=0.501)$. EBT and oral temperature also correlated before and after MCT at baseline $(\mathrm{p}=0.003, \mathrm{r}=$ $0.390)$ and after 15-60 $\min (\mathrm{p}=0.001-0.015, \mathrm{r}=0.325-$ 0.424). Peak oral temperature coincided with peak EBT after both EVH (fig. 1) and MCT (fig. 2).

$\triangle \mathrm{EBT}$ and $\Delta$ oral temperature (defined as the difference between baseline oral temperature and maximum oral temperature after the challenge test) correlated significantly after EVH $(\mathrm{p}=0.001, \mathrm{r}=0.428)$ and MCT $(\mathrm{p}=$ $0.014, r=0.330$; fig. 5 ). No corresponding correlations were seen when comparing $\triangle \mathrm{EBT}$ to axillary or auricular temperature (data not shown).

\section{Exhaled Nitric Oxide}

Baseline levels of exhaled NO did not differ between asthmatic subjects and controls, between atopic subjects and nonatopic subjects, between asthmatic subjects with or without a positive challenge test or between asthmatic subjects with or without ICS treatment. Levels of exhaled NO did not correlate with EBT before or after any of the challenge tests except postsalbutamol after MCT $(\mathrm{p}=0.041, \mathrm{r}=0.277)$. It did not correlate with $\triangle \mathrm{EBT}$. 
Impulse Oscillometry System

No significant correlations were found between EBT (including $\triangle \mathrm{EBT}$ ) and IOS parameters at any time point, or between EBT and the change in any IOS parameter compared to at baseline.

As expected, increases in R5, R20, R5-R20 and AX, and a decrease in X5, were seen in all subjects when comparing baseline values to those measured after MCT. Fres was increased in controls only. R5-R20\%p was significantly higher in asthmatic subjects than in healthy controls after MCT (data not shown), but no other IOS parameters differed at baseline or after MCT.

\section{Discussion}

This study showed that EBT increased significantly 15-30 min after EVH and 5-45 min after MCT, and that no difference in EBT between asthmatic subjects and healthy controls could be detected. Levels of $\mathrm{FEV}_{1} \% \mathrm{p}$ were significantly lower in asthmatic subjects than in controls at all time points; this confirmed that the selection of subjects was adequate. Furthermore, no difference in EBT was seen when comparing subjects with and without BHR after any of the challenge tests.

The increase in EBT seen after EVH and MCT may be a result of increased blood flow following vasodilatation. However, vascular tone alone does not explain the changes in EBT, seeing as EBT decreased from the time point of $60 \mathrm{~min}$ to postsalbutamol after both challenge tests, even though salbutamol is known to increase bronchial blood flow [23]. Other factors such as bronchodilation may also affect EBT, possibly masking the effects of increased blood flow on EBT. Similar studies should be undertaken with the aim of assessing the effects of EVH and MCT on markers of inflammation in exhaled breath condensate, including metabolites [24, 25], leukotriene B4 $[26]$ and isoprostanes $[27,28]$ in patients with asthma. Likewise, it would be worth studying the effects of these challenges on e-nose breathprints $[29,30]$.

A significant increase in EBT was seen already at $5 \mathrm{~min}$ after MCT, in contrast to at $15 \mathrm{~min}$ after the end of hyperventilation. Inhalation of methacholine affects vascular tone and increases bronchial blood flow [18], possibly leading to an early response in EBT. Increased blood flow after EVH is dependent on dehydration of the periciliary fluid and on the release of inflammatory mediators, which might delay the reaction somewhat and give rise to a relatively mild response in both EBT and decrease of lung function. EBT was elevated for a longer period of time following MCT compared to EVH. The duration of an elevation of EBT after airway provocation tests might be related to the intensity of the challenge and the airway response. For example, EBT was elevated for an even greater period of time (at least $60 \mathrm{~min}$ ) following a standardized exercise challenge test [11]. A greater increase in body temperature in general after exercise would not form a satisfactory explanation for this difference, since EBT was elevated independently of the axillary and auricular temperature. The maximum response to exercise (peak EBT) was greater than that after EVH, in spite of the fact that the respective durations of hyperventilation in the two challenge tests are comparable. The increase in cardiac output, with a possible effect on blood flow of the airway mucosa during and after exercise, may provide an explanation for these differences. During EVH, heart rate increases only marginally and blood flow would therefore not be increased to the same extent. Another possibility is that a standardized exercise challenge is a better method of ensuring that ventilation, with subsequent dehydration of the airways, is adequate. While subjects performing EVH may subtly decrease their rate of ventilation to a level perceived as more comfortable, a standardized exercise challenge test performed on a treadmill at approximately $90 \%$ of maximum heart rate ensures that the respiratory rate increases considerably.

In this study, we showed that the maximum change in $\mathrm{FEV}_{1} \%$ p correlated with EBT in asthmatic subjects $5 \mathrm{~min}$ after $\mathrm{EVH}$, but not in the controls. A similar pattern was seen 5 min after the exercise challenge test [11] in all subjects and in the controls, but not when looking at asthmatics separately. The similarities of correlations between EBT and decrease in lung function support the theory that $\mathrm{EVH}$ is equivalent to an exercise challenge test, at least in this perspective. However, while EBT reached its peak after 5 min following the exercise challenge test, maximum median EBT after EVH was seen after $30 \mathrm{~min}$.

The maximum increase in oral temperature correlated with a maximum increase in EBT after both EVH and MCT. Oral temperature displayed the same pattern as EBT after both the provocation tests that we used as well as after exercise, proving that the two temperature measurements are closely related. Although the X-Halo has been validated in previous studies $[2,4]$, one must take into consideration the possibility that since measurements reflect the plateau of the breath temperatures of several expirations registered during a time period of a few minutes, oral temperature in itself may have some effect on the result. This would be in contrast to the singlebreath method described in other studies [5-8]. Auricu- 
lar temperature increased 5-15 min after MCT, which may possibly be explained by a spread of heat to the ear through the Eustachian tube. However, peak auricular temperature did not coincide with the peaks of EBT and oral temperature after MCT. Axillary temperature was decreased after EVH and to a lesser extent after MCT. The explanation for this is not known, but it is possible that the time of rest following arrival at the laboratory was insufficient, resulting in an elevated axillary temperature at baseline. However, in this case, baseline axillary temperature before MCT would most probably also have been affected.

In summary, our findings suggest that EBT is directly related to oral but not to axillary or auricular temperature, regardless of the type of challenge test or level of physical activity. We believe that this connection is a result of increased blood flow due to vasodilatation taking place only in the airways and/or the oral cavity, both being part of the respiratory tract.

Some of the controls in our study displayed BHR after one or both of the airway challenge tests. The prevalence of positive methacholine challenge tests in the general population has been reported to range from $<10 \%$ to $>40 \%$ in various studies, and normal variations in BHR can be expected even among subjects selected for the absence of known potential causes of a positive challenge test, such as asthma [31]. Similar variations are most probable even for indirect tests of BHR, even though they normally display a higher specificity [32].

Exhaled NO has been shown to correlate with EBT in some studies $[7,8]$, but this was not one of our findings. We also found no differences in levels of exhaled NO between asthmatics and controls, between asthmatics with and without ICS treatment or between atopic and nonatopic subjects. As seen by the results of the Asthma Control Test, this study used subjects with relatively mild and well-controlled asthma, possibly representing a different phenotype from that used in studies showing elevated levels of NO in asthmatics. The fact that there was a significant difference in $\mathrm{FEV}_{1} \% \mathrm{p}$ at all times should nevertheless confirm that our selection of asthmatic subjects was representative. EBT has also recently been suggested to correlate with body height [33], but no such correlations were found in our study.

One hypothesis was that airway narrowing, measured as airway resistance by IOS, would affect changes in EBT. However, no such correlations could be seen.

To conclude our findings, we have shown an increase in EBT after both EVH and MCT, reflecting a normal physiological response which is similar in asthmatic subjects and healthy controls. EBT is probably affected by vasodilating agents and increases when lung function declines, although significant correlations between the two are limited. EBT and oral temperature both increase and display significant correlations before and after EVH and MCT, probably reflecting the same processes affecting temperature in the respiratory tract, independently of body temperature in general.

\section{Acknowledgements}

The authors would like to thank Alexander Darlison for assistance with collection of data and research nurse Anna Sikesjö and the rest of the staff at the Research Unit, Respiratory Medicine and Allergology, Skåne University Hospital, for clinical assistance.

This work was supported by grants from the Swedish Heart and Lung Foundation, Swedish Research Council, Evy and Gunnar Sandberg's Foundation, the Österlund Foundation and the Research Foundation of the Swedish Asthma and Allergy Association.

\section{Financial Disclosure and Conflicts of Interest}

The authors report no conflicts of interest. The authors alone are responsible for the content and writing of the paper.

\section{References}

1 Sont JK, Willems LN, Bel EH, van Krieken JH, Vandenbroucke JP, Sterk PJ: Clinical control and histopathologic outcome of asthma when using airway hyperresponsiveness as an additional guide to long-term treatment. The AMPUL study group. Am J Respir Crit Care Med 1999;159:1043-1051.

- Popov TA, Dunev S, Kralimarkova TZ, Kraeva S, DuBuske LM: Evaluation of a simple, potentially individual device for exhaled breath temperature measurement. Respir Med 2007; 101:2044-2050.
-3 Melo RE, Popov TA, Solé D: Exhaled breath temperature, a new biomarker in asthma control: a pilot study. J Bras Pneumol 2010;36: 693-699.

4 Xepapadaki P, Xatziioannou A, Chatzicharalambous M, Makrinioti H, Papadopoulos NG: Exhaled breath temperature increases during mild exacerbations in children with virus-induced asthma. Int Arch Allergy Immunol 2010;153:70-74.

5 Paredi P, Kharitonov SA, Barnes PJ: Correlation of exhaled breath temperature with bronchial blood flow in asthma. Respir Res 2005;6:15.

6 Piacentini GL, Peroni DG, Bodini A, Corradi $\mathrm{M}$, Boner AL: Exhaled breath temperature as a marker of airway remodelling in asthma: a preliminary study. Allergy 2008; 63:484-485.

7 Piacentini GL, Bodini A, Zerman L, Costella S, Zanolla L, Peroni DG, Boner AL: Relationship between exhaled air temperature and exhaled nitric oxide in childhood asthma. Eur Respir J 2002;20:108-111. 
8 Paredi P, Kharitonov SA, Barnes PJ: Faster rise of exhaled breath temperature in asthma: a novel marker of airway inflammation? Am J Respir Crit Care Med 2002;165:181-184.

$>9$ Tanaka H, Yamada G, Saikai T, Hashimoto M, Tanaka S, Suzuki K, Fujii M, Takahashi H, Abe S: Increased airway vascularity in newly diagnosed asthma using a high-magnification bronchovideoscope. Am J Respir Crit Care Med 2003;168:1495-1499.

$>10$ Piacentini GL, Peroni D, Crestani E, Zardini F, Bodini A, Costella S, Boner AL: Exhaled air temperature in asthma: methods and relationship with markers of disease. Clin Exp Allergy 2007;37:415-419.

11 Svensson H, Nilsson D, Bjermer L, Tufvesson E: Exhaled breath temperature increases after exercise in asthmatics and controls. Respiration 2012;84:283-290.

12 Peroni DG, Chinellato I, Piazza M, Zardini F, Bodini A, Olivieri F, Boner AL, Piacentini GL: Exhaled breath temperature and exercise-induced bronchoconstriction in asthmatic children. Pediatr Pulmonol 2012;47:240-244.

-13 Barreto M, Villa MP, Olita C, Martella S, Ciabattoni G, Montuschi P: 8-Isoprostane in exhaled breath condensate and exercise-induced bronchoconstriction in asthmatic children and adolescents. Chest 2009;135:66-73.

-14 Zietkowski Z, Skiepko R, Tomasiak-Lozowska MM, Mroczko B, Szmitkowski M, Bodzenta-Lukaszyk A: RANTES in exhaled breath condensate of allergic asthma patients with exercise-induced bronchoconstriction. Respiration 2010;80:463-471.

15 Zietkowski Z, Skiepko R, Tomasiak-Lozowska MM, Zietkowska E, Bodzenta-Lukaszyk A: Eotaxin in exhaled breath condensate of allergic asthma patients with exercise-induced bronchoconstriction. Respiration 2011;82: 169-176.
16 Anderson SD, Daviskas E: The mechanism of exercise-induced asthma is.... J Allergy Clin Immunol 2000;106:453-459.

17 Salonen RO, Webber SE, Widdicombe JG: Effects of neurotransmitters on tracheobronchial blood flow. Eur Respir J Suppl 1990;12: 630-637.

18 Ward C, Pais M, Bish R, Reid D, Feltis B, Johns D, Walters E: Airway inflammation, basement membrane thickening and bronchial hyperresponsiveness in asthma. Thorax 2002;57:309-316.

19 Global Initiative for Asthma: Global strategy for asthma management and prevention, 2011. http://www.ginasthma.com.

20 ATS/ERS recommendations for standardized procedures for the online and offline measurement of exhaled lower respiratory nitric oxide and nasal nitric oxide. Am J Respir Crit Care Med 2005; 171:912-930.

21 Crapo RO, Morris AH, Gardner RM: Reference spirometric values using techniques and equipment that meet ATS recommendations. Am Rev Respir Dis 1981;123:659-664.

22 Aronsson D, Tufvesson E, Ankerst J, Bjermer L: Allergic rhinitis with hyper-responsiveness differ from asthma in degree of peripheral obstruction during methacholine challenge test. Clin Physiol Funct Imaging 2008;28:81-85.

23 Kumar SD, Emery MJ, Atkins ND, Danta I, Wanner A: Airway mucosal blood flow in bronchial asthma. Am J Respir Crit Care Med 1998;158:153-156.

24 Montuschi P, Paris D, Melck D, Lucidi V, Ciabattoni G, Raia V, Calabrese C, Bush A, Barnes PJ, Motta A: NMR spectroscopy metabolomic profiling of exhaled breath condensate in patients with stable and unstable cystic fibrosis. Thorax 2012;67:222-228.
25 Motta A, Paris D, Melck D, de Laurentiis G, Maniscalco M, Sofia M, Montuschi P: Nuclear magnetic resonance-based metabolomics of exhaled breath condensate: methodological aspects. Eur Respir J 2012;39:498-500.

26 Montuschi P: LC/MS/MS analysis of leukotriene B4 and other eicosanoids in exhaled breath condensate for assessing lung inflammation. J Chromatogr B Analyt Technol Biomed Life Sci 2009;877:1272-1280.

27 Montuschi P, Barnes PJ, Ciabattoni G: Measurement of 8-isoprostane in exhaled breath condensate. Methods Mol Biol 2010;594:7384.

28 Lucidi V, Ciabattoni G, Bella S, Barnes PJ, Montuschi P: Exhaled 8-isoprostane and prostaglandin $\mathrm{E}(2)$ in patients with stable and unstable cystic fibrosis. Free Radic Biol Med 2008;45:913-919.

29 Montuschi P, Mores N, Trové A, Mondino C, Barnes PJ: The electronic nose in respiratory medicine. Respiration 2013;85:72-84.

-30 Bofan M, Mores N, Baron M, Dabrowska M, Valente S, Schmid M, Trové A, Conforto S, Zini G, Cattani P, Fuso L, Mautone A, Mondino C, Pagliari G, D’Alessio T, Montuschi P: Within-day and between-day repeatability of measurements with an electronic nose in patients with COPD. J Breath Res 2013;7: 017103.

31 Hewitt DJ: Interpretation of the 'positive' methacholine challenge. Am J Ind Med 2008; 51:769-781.

32 Anderson SD, Kippelen P: Assessment and prevention of exercise-induced bronchoconstriction. Br J Sports Med 2012;46:391-396.

33 Tavares B, Goncalves I, Gomes S, Jacinto T: Reference values for exhaled breath temperature in healthy subjects aged 17 to 25 years old. Eur Resp J 2012;(suppl 56):3204. 